\title{
ICT-Enabled Citizen Co-production in Excluded Areas - Using Volunteers in Emergency Response
}

Sofie Pilemalm

The self-archived postprint version of this journal article is available at Linköping University Institutional Repository (DiVA):

http:// urn.kb.se/ resolve?urn=urn:nbn:se:liu:diva-160126

N.B.: When citing this work, cite the original publication.

The original publication is available at www.springerlink.com:

Pilemalm, S., (2019), ICT-Enabled Citizen Co-production in Excluded Areas - Using Volunteers in Emergency Response, Electronic Participation, 87-101.

ISBN: 9783030273965 (print), 9783030273972 (online)

https:// doi.org/ 10.1007/978-3-030-27397-2_8

Series: Lecture Notes in Computer Science, ISSN 0302-9743, eISSN 1611-3349, No. 11686

Original publication available at:

https:// doi.org/ 10.1007/978-3-030-27397-2 8

Copyright: Springer Verlag (Germany)

http:// www.springerlink.com/?MUD=MP

Tweet 


\title{
ICT-enabled citizen co-production in excluded areas - using volunteers in emergency response
}

\author{
Sofie Pilemalm ${ }^{[0000-0002-4677-1949]}$ \\ Linköping university, 582 28, Linköping, Sweden \\ Incsespringer.com
}

\begin{abstract}
One of many contemporary public-sector challenges is the increasing socio-economic gaps and excluded areas in many cities worldwide. This study explores ICT-enabled citizen co-production using volunteers as first responders in excluded areas near Stockholm, the capital of Sweden. The study indicates that these volunteers can make a major difference if arriving first at an emergency site, e.g. saving lives by administering CPR and extinguishing fires before they spread. Major challenges relate to individual versus collective engagement, gender aspects and language barriers. Current ICT support, in the form of text messages or a basic app, is deemed sufficient but, for the initiative to expand and enable long-term effective engagement, calibrated solutions matching competence, role and language with incident and area are needed. In a publicsector innovation context, the study highlights the need for future research on digitalized co-production with an explicit focus on the ICT artifact and its cocreation artifact as catalysts for change. In relation to this, this study confirms previous research arguing for the merging of policy science and information systems research in an era of rapid digitalized public-sector transformation, but adds that they need to be complemented by perspectives from sociology, e.g. on gender and ethnicity, in initiatives involving citizens in excluded areas.
\end{abstract}

Keywords: public-sector innovation, co-production, citizen engagement, ICT.

\section{Introduction}

The public sector is undergoing rapid transformation in response to increasing global challenges, e.g. in terms of natural disasters, migration streams, increased socio-economic gaps, urbanization, aging populations, war and terrorism, financial cutbacks and resource shortages [1]. Digitalization has paved the way for various initiatives built around citizen engagement, as one (of many) means to address several of them. This has sometimes been referred to as "do-it-yourself government" as an emerging culture within public-sector innovation [2]. It has been explored using different perspectives and theoretical lenses; for example, co-production [3].

In terms of socio-economic gaps, the tendency in many western countries is towards growing segregation, whereby an increased number of urban sub-areas are characterized by poverty and social exclusion, sometimes to an extent where societal structures are deemed absent and replaced by parallel structures, and where criminality increases 
$[4,5]$. In such areas, research reveals poorer health and school results, higher unemployment, and, not least, a larger number of emergencies than for the rest of the population [6]. For instance, those exposed to intentional urban fires in Sweden more often live in socio-economically disadvantaged sub-areas [4]. In emergency response, volunteerism and citizen engagement initially expanded rapidly within large-scale crisis management [7]. Over the past decade, organizing citizen volunteers as first responders has also gained attention in relation to frequent accidents on a smaller scale [7]. In Sweden, which has been progressive in developing the concept, the idea was first applied in sparsely populated rural areas where civil citizens are often closer to an incident site than professional response organizations $[8,9]$. More recently, it has spread to socially vulnerable municipalities and excluded sub-areas in large cities. The concept is enabled by modern ICT, such as people having access to mobile devices with GPS positioning, which can be integrated with the emergency response organizations' systems for dispatching resources. This study focuses on a brand-new initiative using citizen volunteers as first responders in collaboration with the municipal fire services, in two municipalities outside the capital of Stockholm. The initiative is aimed at improving safety and the effectiveness of first response, and reducing the consequences of emergencies in areas exposed to high rates of crime and accidents. The initiative is studied here as an example of ICT-driven public-sector innovation under the lens of co-production.

\subsection{Study aim and objectives}

The aim of this study is to explore the concept of engaging citizens as volunteer first responders in socially vulnerable areas. Specifically, the objectives include:

- Describing the recruitment and tasks of the volunteers.

- Identifying the distinct features of the ICT artifact as a catalyst for the initiative.

- Identifying the perceived benefits, challenges and needs of the volunteers.

The intended audience is researchers and practitioners in emergency response, those involved in public-sector innovation and citizen co-production initiatives in general, and in excluded areas specifically. The study should have international relevance since volunteerism is growing globally and since our society shares the challenges, even if various countries' structures, regulations and legal mechanisms differ.

\section{Background}

\subsection{Public-sector innovation and co-production}

Public-sector innovation can be traced back to the 1960s. Recent decades, however, have seen an increasing trend of replacing random initiatives with more systematic work and planned innovations, as a response to pressing societal challenges in an era when the public sector's own resources are constrained [10]. It can take various forms and involve public-public, public-private, and/or public-third-sector partnerships. One 
form concerns citizen engagement, which is described from various perspectives, sometimes depending on research discipline. It is possible to speak about co-production, where citizens are involved in the delivery of public policies and services, as part of the conception, design, steering, and management of services $[3,11]$. From the perspective of e-government, it has also been described as a form of "do-it-yourself government" or "we-government," referring to "the re-emergence of citizen coproduction" and where citizens act as partners rather than customers in the delivery of public services, in order to make them more viable and effective [2]. In comparison with earlier forms of e-government, we-government implies that a certain group of citizens takes on certain tasks from the authorities, not only for themselves, but also for their co-citizens. This, in turn, requires that their ICT artifacts are integrated with the authorities' own information systems (IS). Speaking in terms of IS development and research, co-production and we-government can thus be related to concepts of co-creation, co-design, and participatory design (PD) $[3,10,11,12]$. Of particular relevance to the study, it has been argued that designing for and co-creating with vulnerable groups is a key priority to advance and benefit the contemporary service field [13]. In a wider perspective, citizen co-production opens up opportunities for interesting mergers of research disciplines; for example, policy science and IS, a cross-fertilization which has recently been pointed out in relation to government and a public sector undergoing change $[14,15$, 16]. The study therefore applies intertwined co-production/we-government/IS perspectives and relates these to the on-going discussion.

\subsection{Study context: citizen co-production in excluded areas}

It is sometimes claimed that the social contract between citizens and the authorities is crumbling [17]. This is especially notable in an increasing number of urban sub-areas characterized by segregation, ethnic diversity and few opportunities for inclusion in society, where residents experience insecurity and a lack of trust in the authorities and perceive themselves as having little possibility of influencing their environment or lives [4]. Unemployment is usually higher than average, resulting in low socio-economic status, and recruitment to criminality is correspondingly growing, especially among young people [18]. Accidents also tend to strike according to patterns related to such aspects as gender, ethnicity, class, and living area [19]. In this study, these areas are referred to as socially vulnerable areas or excluded areas. This trend is global and in need of handling. Increased citizen engagement could be one way forward.

The study takes place in the context of Swedish emergency response, referring to actors, technologies, procedures and rules, which aim to save lives and minimize human suffering and material damage in emergencies such as traffic accidents, fires and medical matters. In Sweden, various initiatives have been undertaken over the past decade to improve efficiency and overcome long distances by the involvement of various societal resources in day-to-day emergency response, in collaboration with the professional operative response organizations (fire services, ambulance services, and the Public Safety Answering Point (PSAP)). Examples include cross-sector collaboration using entirely new occupations, for example, security guards or civil volunteers, as first responders. In the latter, the concept first spread to sparsely populated rural areas in northern Sweden, where the response organizations are located a long distance from small 
villages. There is thus a large chance that the volunteers will arrive first at the emergency site, providing basic first aid while waiting for professional resources [8, 9]. Over the past few years, similar initiatives have emerged in urban areas, above all located near Stockholm and Gothenburg. Stockholm has a population of about 2 million people if the surrounding municipalities are included, with a rapid expansion in recent decades, due to both urbanization and refugee immigration, not least in 2012-2015.

\section{Methods: the studied initiative and action research}

The studied initiative is taking place in two municipalities outside Stockholm with about 100000 inhabitants each. Here, a major Swedish Fire Response Association has started an initiative that recruits citizens living in socially vulnerable/excluded areas as volunteer first responders. The volunteers are provided with one day of basic training in such areas as first aid, heart-and-lung rescue (CSPR), extinguishing small fires, and acting in single traffic accidents. They also receive a basic backpack containing a first aid kit, reflective vests, pocket masks and hand-held fire extinguishers. The aim of this initiative is twofold; firstly, to create a sense of presence, security and social relations in these areas, to decrease the incidence of intentional fires (mostly in cars), assaults and vandalism. Secondly, if an emergency takes place, to have the volunteers act as first responders for certain alerts. The idea is not to have the volunteers replace the professional response organizations, but rather for them to carry out first response while waiting for the professionals, in order to reduce the response time. To receive alerts, volunteers have to be less than five kilometers away from the emergency site, and acting on the alert is always voluntary. By early 2019, about 80-90 civil volunteers had been recruited and trained in various areas across these municipalities.

The overall study design has the character of action research meaning that the researchers aim to develop and improve the initiative together with the participating actors [20], including the volunteers. This study reports from the first phase (April 2018 to January 2019). Three researchers have been involved in this phase. The author of this paper was involved in all data collection described below.

\subsection{Data collection: semi-structured interviews and focus groups}

The study was performed as a qualitative interview study including four semi-structured interviews and one focus group interview with five respondents (Table 1). In semi-structured interviews, a template or themes are usually applied to guide the interview but no strict adherence to the template is required and respondents are allowed to make other associations during the course of the interview. Focus groups work similarly but enable group dynamics and collective views on a particular phenomenon from a group whose members have experience or knowledge concerning the topic in question [21]. A snowball sample approach [21] was chosen since the initiative is new, emerging and undergoing expansion. For instance, when the study started in spring 2018, only about 10 civil volunteers were in the system and it was deemed important to interview those who had responded to alerts.

First, a focus group interview was held with a fire team consisting of one fire chief and three firefighters. Another fire chief joined for the second half of the interview, and 
continued responding to questions when the team had to respond to an incoming emergency alert. The focus group lasted in total for 90 minutes. All focus group respondents played a role in the volunteer initiative. This was followed by interviews with the instigator of the initiative and the current project leader, who took over from the instigator (both had a background as firefighters), and two civil volunteers who were residents of excluded areas and had acted on several alerts. Each interview lasted about one hour.

For all the data collection, templates that had been used in the earlier project on volunteers in sparsely populated areas [9] were used. However, they were revised to suit the current initiative and urban setting. The templates were also somewhat adapted depending on whether someone from the fire services or a civil volunteer was being interviewed. All interviews were audio-taped and transcribed. For the analysis, a thematic approach was used [21], clustering data into overall themes based on the empirical data and in line with the action-research approach, with a focus on development; for example, benefits, challenges and needs. The author of this paper performed the data analysis and received feedback from one of other researchers on the identified themes.

Table 1: Respondents participating in the study.

\begin{tabular}{|l|l|l|l|l|}
\hline Focus group & Fire chief (1+1) & Firefighters (3) & & 5 \\
\hline Interviews & Project instigator (1) & Project leader (1) & Volunteers (2) & 4 \\
\hline $\begin{array}{l}\text { Total number of re- } \\
\text { spondents }\end{array}$ & & & & 9 \\
\hline
\end{tabular}

\section{Results}

The identified themes are presented in the following. The ICT artifact will receive specific attention but is integrated under the various themes.

\subsection{Recruitment of volunteers}

As mentioned, there are several motivations lying behind this project, of which the most important is to create a sense of presence and security in the studied areas to improve collaboration with the response organizations, and to reduce crime, above all incidents of arson in cars and buildings. A related motivation is gender related, with the hope that women will improve their prospects for integration into Swedish society by becoming volunteers. There is also the hope of a more effective response if an emergency arises, but this is not as pronounced because the initiative is taking place in an urban area where the response times for professional response organizations are relatively short.

In the recruitment process, the fire services have deemed it important to engage people who have a certain social status in the sub-areas. An example could be the priest of a certain church. Another idea is to build on family and social relations; for example, if your relative is a volunteer first responder, you may think twice about setting a car on fire nearby. It has also been shown to be crucial that volunteers who are active in a certain area speak its dominant language and can acts as interpreters, since many people in these areas do not speak Swedish: 
A problem was also that everybody believed the entire block was going to burn to the ground. Everybody who lives there ran to their balconies and were about to jump because they thought they were going to die. There were huge problems and no interpreter in place, no one from the fire station. Then I thought, what the hell, it's time to find out if I can be of any help. (Volunteer 1)

The responders from the fire services described how they have used local interest associations, the municipalities and related real-estate companies for recruitment campaigns. The volunteers confirmed that they received information about the initiative from their respective real-estate companies. The interest has generally been much higher than the fire services expected; they had wanted to start on a small scale. One of the fire chiefs provided an example in which an entire Syrian Orthodox association of about 200 women signed up their interest. This forced the fire services, which pay for all related expenses, to initially turn down many of those who were interested.

An initial fear was that they may recruit those who are involved in criminality. Before volunteers undergo training, therefore, they are first checked with the police to discover if they have a criminal record. To date, this fear appears to be groundless:

Even though it is possible that an individual is known to be a criminal by those living in the area but not by us and we recruit them, then they might feel increased trust in us for creating social benefits... Or it will have the reverse effect [on trust] ....it's a break even....Those into heavy criminality spreading fear will not show interest; they have so much capital violence to manage, a full-time assignment... (Project leader)

\subsection{Dispatching of volunteers and first response tasks}

There are two ways of dispatching the volunteers, depending on sub-area. In some areas they are dispatched by text message lists (Swedish abbreviation: SMS), in which case their mobile phone's GPS functions are connected to the fire services' system for handling incoming alerts. If the type of emergency is one of those described below, the volunteers will receive an SMS if they are on the list and within a radius of five kilometers of the emergency. The SMS displays the position coordinates, the address (road, but not specific number), municipality and type of emergency (Figure 1). A commercial app adapted for the purpose, which is used in other areas, has somewhat more functionality. The principle for dispatching (radius in kilometers) is the same, but the volunteers receive a push notice together with an alert signal. In addition, the app includes a map and when the alert is due a red button is placed in the map, indicating the emergency site. Through this button, the volunteers (receivers of the alert) can also communicate with each other and provide updated information on the emergency (Figure 2). In both cases, it is the fire services back office systems that provides the GPS coordinates, the addresses and the information of the emergency, i.e. the volunteers receive the same basic information as the professional first responders. 


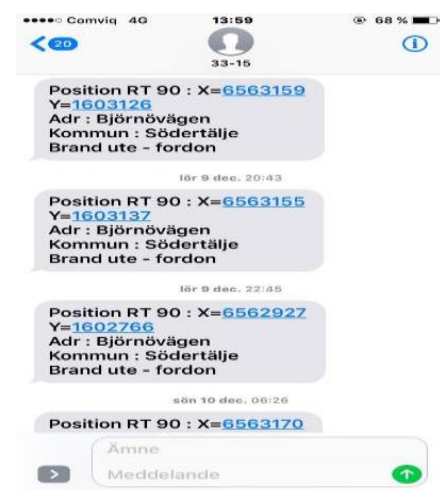

Figure 1. SMS-dispatched ICT solution for volunteers. The example displays outdoor fires in vehicles.

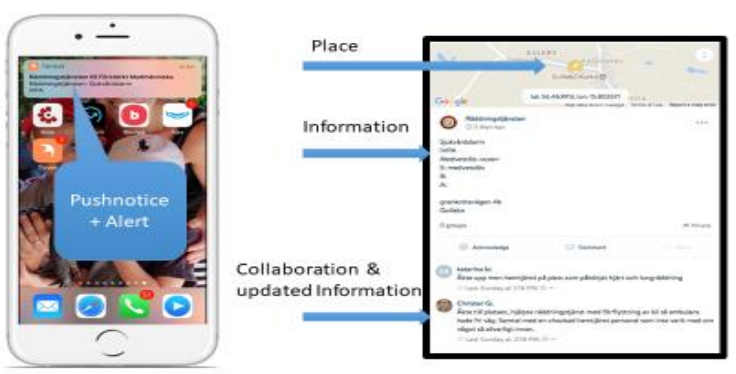

Figure 2. Dispatching of volunteers through the app

The volunteers are dispatched to the following types of emergencies: outdoor fires (e.g. vehicle), fires in building, heart failure, single traffic accidents and drownings. The emergency should not be risky for them (e.g. uncontrolled fires or a shooting) and they should be able to carry out first response using their small backpack equipment kit. The volunteers perform a range of tasks at the emergency site but those reported as most frequent by the volunteers are: extinguishing small fires, checking if the fire has spread and in this case informing the fire services, and backing bystanders and keeping them at a distance when the latter arrives. They have also acted in some single traffic accidents and after assaults (but here they must never intervene but await the police) with basic first-aid tasks (band aids, stopping minor bleeding) and providing comfort. There are heart failure alarms but these are less frequent. One of the volunteers says he has only acted on two heart failure alarms over a period of about a year.

The volunteers receive a debriefing by fire service personnel immediately after a response operation, but no follow ups. But, as stated by one of the volunteers, "the fire station is always open". The volunteers are collectively insured by the fire association. 


\subsection{Perceived benefits}

It is deemed too early to say whether the major aim of the initiative has been fulfilled. However, it is clear that there is great engagement on the part of the volunteers, and a desire to create a safer neighborhood rather than to receive financial compensation. Also, when something does happen, volunteers sometimes arrive before the fire services and a single first response can make a major difference, as illustrated by the following quotes:

I was at home and received an alert concerning a fire near a health center. Thought that they wanted to test me to check how I function. I was the first person at the site, it was a car on fire. I extinguished it completely. (Volunteer 1, first alert).

Was at home, 200 meters from me, went there, they are screaming from the balcony that he's died. Seven floors up. He was on the floor, not breathing, I started heart and lung rescue. He comes back, starts breathing. Two minutes later, the ambulance arrives. He is alive. (Volunteer 1, heart failure alert).

Again, communication and acting as an interpreter are central, as well as having knowledge about the area and knowing the people who live there. This is something the fires services and volunteers agree upon:

I believe very much in this. Above all, they might have knowledge of the area and who is the leader, so to speak. When the police take action, the outcomes are often not that good. (Fire chief, focus group, volunteers backing crowds of people)

I have learnt how to "back" a crowd of people. I know the language, I can tell them that this smoke is a cancer risk. (Volunteer 1).

\subsection{Challenges}

The major perceived challenge is having volunteers actually responding to alerts and going to the incident site. Massive interest in recruitment is not the same thing as actually patrolling the neighborhood or taking action when something happens. There are a few enthusiasts who respond to many alerts, but they are often the only ones responding to that particular alert, making first response an individual task. The project leader believes that a potential explanation is that few volunteers know any firefighters and that "the fire services work in an end room". This might result in hesitancy about intervening in an emergency. He also poses the question of whether economic compensation would after all play a role, and argues that it might have been better to start on a larger scale:

I think I would have started on a larger scale. More volunteers from the very beginning [training/equipping]... to kind of create a feeling of local and not individual engagement.

A related challenge concerns gender aspects. There was a hope that the initiative would pave the way for women to move into society, and many women did express interest. However, one year later, all the active volunteers are men and the project leader 
expresses uncertainty when considering how a female volunteer would be seen; for example, when backing people. Also, a common notion among all the fire service respondents is that communication and learning is top down; i.e., the fire services train the volunteers and tell them what to do, but there is no mechanism for the volunteers to provide feedback or share their knowledge. The project instigator is somewhat selfcritical about this:

This is true, and we devoted no time to them teaching us. It's an important point, that this should go both ways...It's not completely unproblematic having a group of more or less ethnic Swedes going to XXX [sub-area] and telling people "this is how it works".

As the initiative progressed, Facebook (FB) groups were started in various sub-areas of the municipality. However, there is much more activity in those groups that are based in more well-off areas, where the majority of volunteers are of Swedish ethnicity. Neither of the two volunteers in the interviews have joined a FB group.

Another perceived challenge is, again, language. It is not optimal to send just any volunteer, but rather one who knows the particular language of those involved in an emergency or the dominant language in the given sub-area. There is also the general challenge of evaluating the concept, both qualitatively and in terms of efficiency; for example, lives saved, response times, and monetary value. Since this is an initiative in progress, no such plans had been made at the time of this study. However, they are important for motivating the spread of the concept among municipalities and for decision-making by politicians, among others.

\subsection{Needs}

The fire-service respondents agree that the major need is to expand the initiative, in terms of having more volunteers acting as safety persons/first responders, making it locality rather than individual based, as expressed by the project leader in January 2019:

As things are now, the project has not really expanded to the extent that we want it to. I think that with the technical prerequisites that we have and with the design that technology makes possible...it should be possible to expand more. The technology, at the moment, does not limit us.

The volunteers also see the need to expand, and one of them suggested that they partake in the recruitment process; for example, by engaging colleagues at their workplace so that they could go on alerts together, knowing each other beforehand. Apart from this, the volunteers did not express many needs, even though they were asked explicitly. One of them mentioned a warmer jacket and that exercises are good.

A concrete need, however, concerns the ICT solution. The volunteers being interviewed relied on the SMS lists and mentioned that they sometimes receive the wrong address from the rescue services, a problem they share with the fire services (since it is the back office systems that sometimes send incorrect coordinates or information e.g. indicating roads), thus delaying response time: 
I don't always know exactly what building or tenement. With a straight address, it would be perfect. In ... [sub-area] there are two roads that are often mixed up in the SMSs. Not even the fire station always knows. [Volunteer 2]

In the app version, this have partly been addressed by the supplier adding an additional map to navigate among e.g. roads that cross or run in parallel, and the volunteers would thus like to have an extended app version that includes a map and inbuilt GPS guidance to the emergency site. Also, the project leader mentioned the importance of the app but that some structure, templates and matching is needed to send the "right" volunteer to the "right" site, reaching different roles, competences and language groups:

If a certain group of immigrants becomes so dominant that we cannot reach that group, then we would need an app that could reach that specific group.

\section{Discussion: digitalization as an enabler of public-sector innovation and co-production}

Public-sector innovation is rapidly transforming our society at a global level, as are initiatives directed specifically towards citizen engagement and co-production [2, 3]. The emerging trends all feature digitalization and modern ICT as an enabler. Nevertheless, as argued by [9], there are relatively few studies (in emergency response, [7] is an exception), that focus explicitly on the direct relation between co-production and ICT artifacts, even though it has been pointed out that ICT can support co-production [22]. Even fewer, if any, studies focus explicitly on the ICT artifact itself, as a catalyst of the co-production. This study's findings illustrate the need to bridge this gap. At first glance, the initiative seems broad and the ICT artifact plays a less than central role, with a basic SMS solution working sufficiently in most cases, even though maps and GPS guidance have been requested. However, data analysis indicates that, for the initiative to be successful and expand, the design of the ICT artifact can contribute significantly. Future app solutions should be able to handle calibration of the volunteer concept; for example, matching availability, competence, role, and language with a specific emergency situation and/or sub-area, by adding functions allowing for dynamic resource dispatching. In order for the whole system to work, there is the corresponding need to do a thorough analysis of the necessary features and interfaces in the fire services back office systems who are to provide this information. Also the overall infrastructure need to be handled, not the least since the office systems sometimes send the wrong address and/or inexact coordinates. In terms of service design, an emergency response process can be divided into two parts, the service-providing process and the services supporting process [23]. Two pay attention to both these processes, including giving correct information to mobile solutions with attractive, easy-to-handle interfaces, and to improved communication between the fire services and the volunteers, may also contribute to more volunteers acting on the alerts. This in its turn includes the necessity to involve additional stakeholders of e.g. the fire services, the PSAP, the suppliers of the backoffice systems, and possibly the ambulance services.

Also, in many sub-areas there are frequent alerts but few volunteers responding to them. A more secure solution with function allowing withdrawal if an emergency should turn into something that is dangerous to the volunteers (e.g. toxic fumes, gunfire) 
is added, this may reduce fear about responding to an alert and stimulate long-term engagement. In relation, similar studies in rural areas [9] have shown that the volunteers, even when collective insurances are provided, are not sufficiently protected by the current Swedish legal system. To address policy and liability issues seem even more important in areas exposed to high rates of criminality risk, and may also influence the volunteer engagement in a positive way.

From a wider public-sector perspective, the bi-directional influence of technology and various forms of governance has been recognized for over a decade and pointed out recently $[24,25]$. Relating this to the research field of IS, the discipline has often drawn upon other disciplines when needed [26]. Several recent studies have claimed the benefits of and need for a cross-fertilization of policy science and IS research perspective, relating explicitly to emerging forms of government in an era of digitalization $[14,15,16]$. This study's finding are in line with this research since digitalization/ICT development needs to consider e.g. regulations and laws on what volunteers are allowed to do and what information the alerts can and cannot include. Below, this discussion is taken further, arguing for a wider integration of research perspectives, when turning to excluded areas and initiatives involving the residents living there.

\subsection{Citizen engagement, co-production and co-creation in excluded areas}

Socially vulnerable and/or excluded areas are not new phenomena, in either western or non-western countries, and parallel societal structures and gang criminality have been studied for a long time [5, 27]. As socio-economic gaps are expanding rapidly, related challenges now also include countries where thus far they have not been so tangible. Sweden is a typical example. The country took many immigrants during the refugee streams of 2012-2016, and is currently struggling to provide them with opportunities for integration and access to the Swedish labor market. Relating this to co-production, citizen engagement initiatives from "the inside", where a community's own residents are recruited to handle criminality and to work with (instead of against) the police have long existed, for example, in shantytowns across the world; albeit not without challenges. Still, [28] argues that more research on city neighborhoods affecting the will to engage in co-production, is needed. Their own study concludes that:

The answer is...straightforward. Neighbourhoods do make a difference in explaining coproduction. However, the social capital, rather than the social status, of the neighbourhood explains the difference between neighbourhoods (p.105).

This notion may contribute to explaining parts of this study's results, where the volunteers seem willing to engage but less secure about acting as a safety person or first responder. When making a brief comparison with other parts of Sweden, in rural, sparsely populated areas dominated by people of Swedish ethnicity, a different picture emerges (a full comparison is not possible since these studies have spanned longer time periods with more volunteer respondents). Here, volunteerism is a collective effort based on long-term social relations, sometimes also including the victims of accidents. Volunteers never go on an alert alone, and they have been more active in both putting explicit requests to the fire services; for example, for trauma support (while one of the volunteers in this study claimed that this is not needed because he had seen worse things 
in his home country). They also suggested added functionality to their dispatch ICT solutions, sometimes even implementing their own functions [9].

In relation to this, co-production is often related to co-creation [3], but as increasing numbers of ICT applications are easily available off-the-shelf from commercial suppliers, co-creation of the artifact itself is often forgotten. This is evident also in this study where the commercial app that some-sub areas use has not been created together with users, and do not include the functions for GPS navigation, calibration, language and withdrawal as suggested in section 5 above. This can be compared to [9], in which a mobile app prototype was developed together with end-users (semi-professionals and volunteer first responders in rural areas) along with the surrounding infrastructure (e.g. training, equipment, legal aspects), even though commercial applications for the purpose existed. This resulted in additional and partially different functions, based on user needs and in line with other features of the collaborations, which might contribute to a more efficient first response and long-term engagement. Co-creation, and corresponding IS development approaches that include user involvement, lean on the active participation of users, when developing both the ICT artifacts themselves and the surrounding infrastructure $[12,29]$. In particular, PD, which has clear political and ideological roots, has been applied to provide exposed societal groups with an opportunity to influence their own situation and environment; for example, in urban planning, in third-world countries, and among charities working for homeless people [30]. Gender relations have also been highlighted by the PD community; for example, how they affect power structures in design groups [31]. The need to achieve the co-creation/PD of ICT support is also highlighted by this study. But this implies that you have volunteers to work with in the first place. To date, relatively few volunteers go on the alerts and women volunteers do not exist at all. It was also perceived as difficult to access the volunteers as study respondents (they did not want to be interviewed, which may have been due to such issues as language barriers). The challenges are in line with a recent study on six co-design sessions, suggesting that vulnerable user groups cannot be approached in the same way as in conventional user involvement processes, and proposing alternative design frameworks and inter-sectionalist perspectives [32]. Leaning on co-creation, co-design and PD such frameworks and methods for user involvement should thus be considered in future expansion of the collaboration and design of related infrastructure and ICT artefacts. It is also plausible that the initiative would benefit from adding research perspectives from others disciplines, to expand the knowledge base and enable participation. Examples may include sociology, inter-sectionalist perspectives, and criminology. The author of this study has previously argued that there is a need for pronounced inter-disciplinary development teams in the case of emerging collaborative forms of public-sector innovation, including cross-sector collaboration and the use of volunteers [8]. Adding the above competences to more traditional systems (or business) development teams seem important in the context of the current study.

\section{Conclusion and future work}

This study set out to explore the concept of citizen co-production engaging them as volunteer first responders in socially vulnerable areas with a focus on aspects including the benefits, challenges and needs, and with the ICT artifact as a catalyst. The study 
concludes that volunteers with basic equipment and training can make a significant difference if they arrive first at an emergency site. The major challenge is actually having them respond to an alert and go to the site. Other challenges relate to gender and to increasing the opportunities for immigrant women in Swedish society, to language barriers, and to changing the one-way communication from the fire services to the volunteers into a two-way flow. The ICT solutions provided are basic and accessible because they are installed on the volunteers' own mobile phones. Still, they are central to engagement, allowing for the dispatching of volunteers who are near to an emergency. Current solutions work sufficiently well, but for optimal usage and expansion of the initiative, ICT solutions supporting dynamic resource allocation (role, competence, language, situation), communication among volunteers and withdrawal functions are suggested.

Previous research has argued that the need to mix perspectives from IS research with policy science becomes particularly pressing in a public sector where new government forms relying on digitalization - for example, governance, policy networks, co-production/we-government, and citizen engagement - are rapidly emerging $[14,16]$. In particular, policy and liability issues needs to be addressed in the emerging volunteer first responder initiatives. An additional conclusion drawn from this study is that additional inter-sectional perspectives and disciplines, not least from the field of sociology, become equally important, in this and similar initiatives, in a society where they are likely to increase. Sweden is perceived as progressive in terms of organized, long-term, civil citizen engagement in emergency response while most international studies tend to focus on issues such as on-site volunteers, large-scale crisis management and crowdsourcing [9]. As pointed out by [9], the types of emergencies have both similarities and differences but to be able to use the same volunteers in them would be beneficial, since they would be accustomed to the ICT solutions and work procedures. This indicates that this study could provide inspiration for similar initiatives but also in relation to large-scale crisis management. A limitation of the study is that only two volunteers were interviewed and thus the perspective from the fire services is most prevalent. At the same time, the pictures painted by the fire services and the volunteers overlap in many respects, somewhat compensating for this.

In future work, the app will be further developed and also connected to fire detectors in a number of selected tenements, to also include unintentional fires, for which excluded areas are also over-represented [18]. Research and co-creation/co-design will be continued with specific attention to vulnerable groups, e.g. in workshops and focus groups, to reach more volunteers, the municipalities, the fire services, the PSAP, and other relevant stakeholders, in order to address the challenges and needs identified in this study. The gender and ethnicity aspects will be addressed by involving a researcher who has studied them previously in IS, public-sector, and emergency-response contexts. Qualitative and quantitative variables will be identified, in order to be able to evaluate the initiative and its transferability to other, similar contexts, both in Sweden and internationally. At a more general level, it is of specific interest to look further into how the original concept, first developed in sparsely-populated, rural areas, can be transferred to urban contexts, and what modifications, for example, in training and the handling of challenges, should take place.. In relation to large-scale crises, future research could focus on this double use of volunteers, in Sweden not the least since the 
government is currently planning for large-scale digitalized coordination of volunteers, in the after-math of the 2014 and 2018 widespread wild forest fires.

\section{Acknowledgements}

This study has been made possible by financial support from the Swedish Civil Contingencies Agency and the Swedish Fire Research Board.

\section{$1 \quad$ References}

1. Haddow, G., Bullock, J., Coppola, D. P.: Introduction to emergency management. 5th edn. Butterworth-Heinemann, Waltham, MA (2013).

2. Linders, D.: From e-government to we-government: defining a typology for citizen coproduction in the age of social media. Government Information Quarterly 29(4), 446-454 (2012).

3. Alford, J., O'Flynn, J.: Rethinking public service delivery: managing with external providers. Palgrave Macmillan, Hampshire, UK (2012).

4. Guldåker, N., Hallin, P-O.: Spatio-temporal patterns of intentional fires, social stress and socio-economic determinants: a case study of Malmö, Sweden. Fire Safety Journal 70, 7180 (2014).

5. Chalfin, A., McCrary, J.: Criminal deterrence: a review of the literature. Journal of Economic Literature 55(1), 5-48 (2017).

6. David, E., Enarson, E.: The women of Katrina: how gender, race, and class matter in an American disaster. Vanderbilt University Press, Nashville, TN (2012).

7. Díaz, P., Carroll, J. M., Aedo, I.: Coproduction as an approach to technology-mediated citizen participation in emergency management. Future Internet 8(3), 41 (2016).

8. Pilemalm, S.: Participatory design in emerging civic engagement initiatives in the new public Sector: applying PD concepts in resource-scarce organizations. ACM Transactions on Human-Computer-Interaction 5(1), 5-26 (2018).

9. Ramsell, E., Pilemalm, S., Andersson Granberg, T.: Using volunteers for emergency response in rural areas: network collaboration factors and IT support in the case of enhanced neighbors. Proceedings of the 14th International Conference on Information Systems for Crisis Response and Management (ISCRAM), Albi, France (2019).

10. AvBason, C.: Leading public-sector innovation: co-creating for a better society. 2nd edn. The Policy Press, Bristol, UK (2018).

11. Ostrom, E.: Crossing the great divide: coproduction, synergy, and development. World Development 24(6), 1073-1087 (2016).

12. Schuler, D., Namioka, A. (eds.): Participatory design: principles and practices. Lawrence Erlbaum Associates Inc, Hillsdale, NJ (1993).

13. Ostrom, A.L., Bitner, M.J., Brown, S.W., Burkhard, K.A., Goul, M., Smith-Daniels, V., Demirkan, H.,Rabinovich, E.: Moving forward and making a difference: research priorities for the science of service. Journal of Service Research 13(1), 4-36 (2010).

14. Melin, U., Wihlborg, E.: Balanced and integrated e-government implementation: exploring the crossroad of public policy-making and information systems project management processes. Transforming Government: People, Process and Policy 12 (2), 191-208 (2018).

15. Janowski, T., Pardo, T. A., Davies, J.: Government information networks: mapping electronic governance cases through public administration. Government Information Quarterly 29(1), 1-10 (2012). 
16. Gil-Garcia, J. R., Dawes, S. S., Pardo, T. A.: Digital government and public management research: finding the crossroads. Public Management Review 20(5), 633-646 (2018).

17. Wijkström F., Zimmer, A. (eds.): Nordic civil society at a cross-roads: transforming the popular movement tradition. Nomos, Baden-Baden (2011.)

18. Urinboyev, R:. Migration and parallel legal orders in Russia. Aleksanteri Insight-Expert Opinion Series 4, (2016).

19. Sefyrin J., Pilemalm, S.: "It's more important to be fast than to be informed": gender, age, disability and ethnicity in relation to IT in the Swedish Rescue Services. Proceedings of the 13th international conference on Information Systems for Crisis Response and Management (ISCRAM), Rio de Janeiro, Brazil (2016).

20. Denzin N., Lincoln Y. S.: Entering the field of qualitative research: strategies of qualitative Inquiry. Sage Publications, Thousand Oaks, CA (1998).

21. Myers, M.: Qualitative research in business and management. Sage Publications, Thousand Oaks, CA (2009).

22. Verschuere, V., Brandsen, T., Pestoff, V.: Co-production: the state of the art in research and the future agenda. VOLUNTAS: International Journal of Voluntary and Non-profit organisations 23(4), 1083-1101 (2012).

23. Kling, R., McKim, G., King, A.: A bit more to IT: scholarly communication forums as sociotechnical interaction networks. Journal of the American Society for Information Science and Technology 54(1), 47-67 (2003).

24. Shan, S., Wang, L., Li, L.: Modeling of emergency response decision-making process using stochastic Petri net: an e-service perspective. Information Technology and Management 13 (4), 363-376 (2012).

25. Loukis, E., Janssen, M., Dawes, S., Zheng, L.: Evolving ICT and governance in organizational networks: conceptual and theoretical foundations. Electronic Markets 26(1), 7-14 (2016).

26. Watson, R. T., Kelly, G. G., Galliers, R. D. Brancheau, J. C.: Key issues in information systems management: an international perspective. Journal of Management of Information Systems 13 (4), 91-115 (1997).

27. Klein, M., Maxson, C.: Street gang patterns and policies. Oxford University Press, Oxford (2006).

28. Thijssen, P., van Dooren, W.: Who you are/where you live: do neighborhood characteristics explain co-production? International Review of Administrative Sciences 82(1), 88-109 (2015).

29. Hillgren P., Seravalli A., Emilson A.: Prototyping and infrastructuring in design for social innovation. CoDesign, 7(3-4), 169-183 (2011).

30. Halskov, K., Brodersen Hansen, N. B.: The diversity of participatory design research practice at PDC 2002-2012. International Journal of Human-Computer Studies 74, 81-92 (2015).

31. Balka, E.: Participatory design in women's organizations: the social world of organizational structure and the gendered nature of expertise. Gender, Work \& Organization 4(2), 99-115 (1997).

32. Dietrich, T., Trischler, J., Schuster, L., Rundle-Thiele, S..: Co-designing services with vulnerable consumers. Journal of Service Theory and Practice 27 (3), 663-688 (2017). 